\title{
A New Cubic Equation of State for Predicting Phase Behavior of Hydrocarbons
}

\author{
A. Dashtizadeh ${ }^{1}$, G.R. Pazuki ${ }^{2 *}$, V. Taghikhani ${ }^{3}$ and C. Ghotbi ${ }^{3}$ \\ 1 South Pars Gas Complex, Boushehr, Assaluyeh - Iran \\ 2 Department of Biochemical Engineering, Malek ashtar University of Technology, Tehran - Iran \\ 3 Department of Chemical and Petroleum Engineering, Sharif University of Technology, Tehran - Iran \\ e-mail: af_dashtizadeh1355@yahoo.com - ghpazuki@yahoo.com \\ * Corresponding author
}

\begin{abstract}
Résumé - Une nouvelle équation d'état cubique pour prédire le comportement de phase d'hydrocarbures - Nous présentons une nouvelle équation d'état cubique à deux paramètres. Les paramètres de la nouvelle équation d'état sont considérés dépendant de la température. Pour calculer les propriétés thermodynamiques d'un hydrocarbure pur, cette équation d'état nécessite de connaître la température critique, la pression critique et le facteur acentrique des hydrocarbures. L'équation d'état proposée est utilisée pour effectuer des calculs PVT et d'équilibre vapeur-liquide de différents hydrocarbures purs et de mélanges de fluides. Les résultats sont comparés à ceux obtenus par deux équations d'état cubiques utilisées classiquement. Les comparaisons indiquent que la nouvelle équation d'état permet d'améliorer la précision des résultats.
\end{abstract}

\begin{abstract}
A New Cubic Equation of State for Predicting Phase Behavior of Hydrocarbons - In this work, a two parameter cubic equation of state is presented. The parameters of the new cubic equation of state are considered temperature dependent. For calculating the thermodynamic properties of a pure hydrocarbon, this equation of state requires the critical temperature, the critical pressure and the acentric factor of hydrocarbon. The proposed equation of state is applied for PVT and VLE calculations of different pure hydrocarbons and fluid mixtures. The results are compared with those obtained by two commonly used cubic equation of state. The comparisons indicate that the new equation of state yields better results.
\end{abstract}




\section{NOTATION}

$\begin{array}{ll}a, b & \text { parameters in the new EOS } \\ a_{c}, b_{c} & \text { parameters at critical point } \\ H & \text { enthalpy } \\ k_{i j} & \text { binary interaction } \\ m & \text { parameter of Equation (3) } \\ m_{1}, m_{2} \text { and } m_{3} & \text { parameters of Equation }(11) \\ n & \text { parameter of Equation (12) } \\ n p & \text { number of data point } \\ O F & \text { objective function } \\ P & \text { pressure } \\ P_{c} & \text { critical pressure } \\ P_{e x p} & \text { experimental pressure } \\ P_{c a l} & \text { calculated pressure } \\ \mathrm{PR} & \text { Peng-Robinson EOS } \\ \mathrm{R} & \text { ideal gas constant } \\ \mathrm{RK} & \text { Redlich-Kwong EOS } \\ \mathrm{S} & \text { entropy } \\ \mathrm{SRK} & \text { Soave-Redlich-Kwong EOS } \\ T & \text { temperature } \\ T_{c} & \text { critical temperature } \\ T_{r} & \text { reduced temperature } \\ v & \text { volume } \\ v_{c} & \text { critical volume } \\ v_{t p} & \text { volume at triple point } \\ y_{1} & \text { mole fraction of component (1) } \\ Z & \text { compressibility factor } \\ Z_{r e p} & \text { compressibility factor of repulsive } \\ Z_{a t t r} & \\ Z_{c} & \end{array}$

\section{Greek Letters}

$\begin{array}{ll}\alpha, \beta & \text { reduced temperature function of the new } \\ \varepsilon, \gamma, \delta & \text { EOS } \\ \rho_{\text {exp }}^{1} & \text { parameters of Equation (3) } \\ \rho_{\text {cal }}^{1} & \text { calculated liquid density } \\ \eta & \text { packing fraction } \\ \eta_{\max } & \text { maximum packing fraction (MPF) } \\ \varphi & \text { fugacity coefficient } \\ \Omega_{p}, \Omega_{d} & \text { weighting parameters. }\end{array}$

\section{INTRODUCTION}

Equations of state have been used to predict phase equilibria in refinery, petroleum reservoir and other chemical industries. Also properties of compounds such as vapor pressure, density of vapor and liquid, thermal properties and solubility of substances in supercritical fluids are calculated based on equations of state (Johnston et al., 1982; Hartono et al., 1999; Madras et al., 2003). Cubic equations of state are currently the equations of state considered most applicable for such calculations. Cubic equations of state can be classified into two categories:

- The cubic equations with two parameters for repulsive and attractive terms such as Van der Waals (Vdw) (1873), Redlich-Kwong (1949), Soave-Redlich-Kwong (1972) and Peng-Robinson (1976), etc.

- The cubic equations with three or more parameters such as Patel-Teja (1982) and Patel-Teja-Valderrama (1990), etc.

Although increasing the number of parameters makes a cubic equation of state more accurate for calculating pure component properties, the extensions of the equation of state to mixtures becomes more difficult, i.e. more mixing rules are required. The PR and SRK equations of state are the best twoparameter cubic equation of state among the others. Many attempts have been made to improve the prediction ability of these two cubic equations of state. Often, in these modified equations of state attractive parameters generally are considered a function of the reduced temperature and the acentric factor and repulsive parameter is keep constant. Of course, there are many equations of state where the repulsive parameter is considered a function of the temperature. For example, Riazi and Mansoori (1993) and Nasrifar and Moshfeghian (2004), etc. The poor volumetric behavior of $\mathrm{Vdw}$ equations of state may be removed by considering the importance of the role of repulsive forces in the behavior of fluids. Recently, Mohsen-Nia et al. (2003) introduced a new method to determine a suitable repulsive term for cubic equations of state. In this work, based on this method, a new two-parameter cubic equation of state is presented. Both parameters are considered temperature dependent. Using this equation of state, the vapor pressure, the liquid density, the vapor volume, the enthalpy and entropy of vaporization for pure hydrocarbons are calculated. Then the proposed equation is extended to mixtures. These results are compared with those obtained from the equations of state frequently used for thermodynamic and fluid phase equilibrium. The comparisons show that the new cubic equation of state has better results than other two equations of state.

\section{PRESENTATION OF THE NEW EQUATION OF STATE}

The compressibility factor, $Z$, based on perturbation theory is written as (Malanowski and Anderko, 1992):

$$
Z=Z_{\text {rep }}+Z_{\text {attr }}
$$

where $Z_{\text {rep }}$ is the hard-sphere term for repulsive term (unperturbed term) and $Z_{\text {attr }}$ is the compressibility factor for attractive term (perturbed term). 
We propose a hard-core equation of state based on packing fraction $\eta$, as below:

$$
Z_{\text {rep }}=\frac{1+\delta \eta}{1-\varepsilon \eta} ; \quad \eta=\frac{b}{4 v}
$$

Therefore, a new cubic equation of state is defined based on SRK and RK equations of state attractive term as:

$$
Z=\frac{v+\delta b}{v-\varepsilon b}-\frac{a}{R T^{m+1}(v+\varepsilon \gamma b)}
$$

By choosing, $m=0, \gamma=\varepsilon=1$ the attraction term of the new cubic equation of state can be reduced to the attractive term of SRK equation of state:

$$
Z=\frac{v+b}{v-b}-\frac{a}{R T(v+b)} \quad \eta \leq 0.6
$$

By applying the critical point constrains the parameters $a$ and $b$ are calculated as:

$$
\begin{aligned}
& a_{c}=0.47448 \frac{R^{2} T_{c}{ }^{2}}{P_{c}} \\
& b_{c}=0.06824 \frac{R T_{c}}{P_{c}} \\
& Z_{c}=0.333
\end{aligned}
$$

In order to test the validity of the new cubic equation of state the maximum packing fractions (MPF) for different hydrocarbons can be determined by considering the triple point and critical density of hydrocarbon according to this equation of state. Minimum volume $\left(v_{\min }\right)$ is the smallest molar volume of hydrocarbons which approximately define the molar volume at the triple point. The maximum packing fraction is calculated at minimum volume for hydrocarbon as (Mohsen-Nia et al., 1995):

$$
\eta_{\max }=0.103\left(\frac{v_{c}}{v_{t p}}\right)
$$

Where in the above equation $v_{c}$ and $v_{t p}$ are molar volumes at critical point and triple point, respectively. The maximum packing fractions (MPF) of various hydrocarbons are reported in Table 1.

The results of this table show that the maximum packing fractions are in the allowable range of $0 \leq \eta \leq 0.6$ where the repulsive part of Equation (3) accurately represents the Scott hard-sphere equation of state. For predicting vapor pressure, liquid density and vapor volume of hydrocarbons, it is entirely sufficient to introduce temperature dependent attractive and repulsive parameters.
TABLE 1

The maximum packing fraction (MPF) of various hydrocarbons calculated from the new cubic equation of state

\begin{tabular}{l|c}
\hline$\eta_{\max }$ & Hydrocarbon \\
\hline 0.3323 & $\mathrm{CH}_{4}$ \\
0.3940 & $\mathrm{C}_{2} \mathrm{H}_{6}$ \\
0.4254 & $n-\mathrm{C}_{4} \mathrm{H}_{10}$ \\
0.4771 & $n-\mathrm{C}_{8} \mathrm{H}_{18}$ \\
0.3743 & $\mathrm{C}_{2} \mathrm{H}_{4}$ \\
0.3812 & $\mathrm{CH}_{3} \mathrm{Cl}$ \\
0.5136 & $n-\mathrm{C}_{10} \mathrm{H}_{22}$ \\
0.4520 & $\mathrm{C}_{3} \mathrm{H}_{6} \mathrm{O}$ \\
0.4090 & $\mathrm{CHC}_{13}$ \\
\hline
\end{tabular}

It is convenient to express the parameters $a$ and $b$ as a product of its value at the critical point and dimensionless functions of temperature and acentric factor:

$$
\begin{aligned}
& a=a_{c} \alpha\left(T_{r}, \omega\right) \\
& b=b_{c} \beta\left(T_{r}, \omega\right)
\end{aligned}
$$

Several empirical and theoretical extensions of the attractive and repulsive terms have been proposed. In this work, we propose three parameter forms of the $\alpha$ function and a linear temperature function for the $\beta$ function in the following form:

$$
\begin{gathered}
a=a_{c}\left[1+m_{1}\left(1-T_{r}\right)+m_{2}\left(1-T_{r}\right)^{2}+m_{3}\left(1-T_{r}\right)^{3}\right]^{2} \\
b=b_{c}\left[1+n\left(1-T_{r}\right)\right]
\end{gathered}
$$

The presented function form for repulsive and attractive term, expressed by Equations (11) and (12) satisfies the basic theoretical conditions for these functions at the critical point:

$$
\left[\alpha\left(T_{r}, \omega\right)\right]=\left[\beta\left(T_{r}, \omega\right)\right] \rightarrow 1 \quad \text { at } \quad T_{r} \rightarrow 1
$$

The parameters of $m_{1}$ to $m_{3}$ and $n$ are determined by using the following objective function:

$$
O F=\sum_{i=1}^{n p}\left\{\Omega_{p}\left|\frac{P_{c a l}-P_{\exp }}{P_{\exp }}\right|_{i}+\Omega_{d}\left|\frac{\rho_{c a l}^{l}-\rho_{\exp }^{l}}{\rho_{\exp }^{l}}\right|_{i}\right\}
$$

Where in Equation (14) $\Omega_{p}=0.8$ and $\Omega_{d}=0.2$. The general form of the parameters in Equations (11) and (12) are presented below:

$$
\begin{aligned}
& m_{1}=0.2513+0.4178 \omega-0.0207 \omega^{2} \\
& m_{2}=-0.1382-0.5923 \omega-1.0493 \omega^{2} \\
& m_{3}=0.1931+1.3955 \omega+0.1961 \omega^{2} \\
& n=0.2155-0.9069 \omega-0.206 \omega^{2}
\end{aligned}
$$




\section{RESULTS}

The proposed cubic equation of state is applied to calculate phase behavior of various pure hydrocarbons and mixtures of fluids. The vapor pressure and saturated liquid density are the most important properties of pure fluids. However, once an equation of state is developed, it is usually applied to calculate many properties. The thermodynamic relations for the new equation of state are presented in Table 2.

The vapor pressure, saturated liquid density and vapor volume of 20 pure hydrocarbons from the new cubic equation of state are compared with experimental data as well as with the predictions given by the SRK and PR equations of state. Among the 20 pure hydrocarbons, the new cubic equation of state predicts the vapor pressure of 12 compounds better than both the PR and SRK equation of state.

The average of absolute deviations (AAD\%) of the predicted vapor pressure using the new cubic equation of state is $1.110 \%$ where as it is $1.219 \%$ for the PR equation of state and $1.333 \%$ for the SRK equation of state. It was also found that the new cubic equation of state predicts the saturated vapor pressure of the pure hydrocarbons much better than the PR and the SRK equation of state. The average of absolute deviations of the predicted saturated liquid densities by use of the new cubic equation of state, the PR equation of state and the SRK equation of state were found to be $6.116,5.067$ and $11.775 \%$, respectively. Also, Table 3 shows that the predictions of the vapor volume by the PR and the SRK equation of state are better than the new cubic equation of state but the average absolute deviation of the new equation of state is acceptable. The average of absolute deviations of the predicted vapor volumes are 3.389, 1.825 and $1.627 \%$, respectively. Table 4 shows the enthalpy and the entropy of vaporization calculated from the three equations of state. It was found that the average of absolute deviations of the predicted enthalpies of vaporization of the 20 hydrocarbons using the new equation of state, the PR and the SRK equations of state are 2.559, 2.077 and 2.619\%, respectively. The average of absolute deviations of the predicted entropies of vaporization of the 15 hydrocarbons using the new equation of state, the PR and the SRK equations of state are $2.714,2.323$ and $3.008 \%$, respectively.

These results obtained from the new cubic equation of state are better than those obtained from the PR and SRK equation of state. Figure 1 shows the experimental and the prediction results of saturated vapor pressure of many hydrocarbons.

Figure 2 shows the prediction and the experimental data of liquid and vapor densities of different hydrocarbons.

In Figure 3, the experimental and predicted pressureenthalpy of many hydrocarbons is presented. Figure 4 shows the entropy of vaporization of some hydrocarbons using the new cubic equation of state. These figures (1-4)

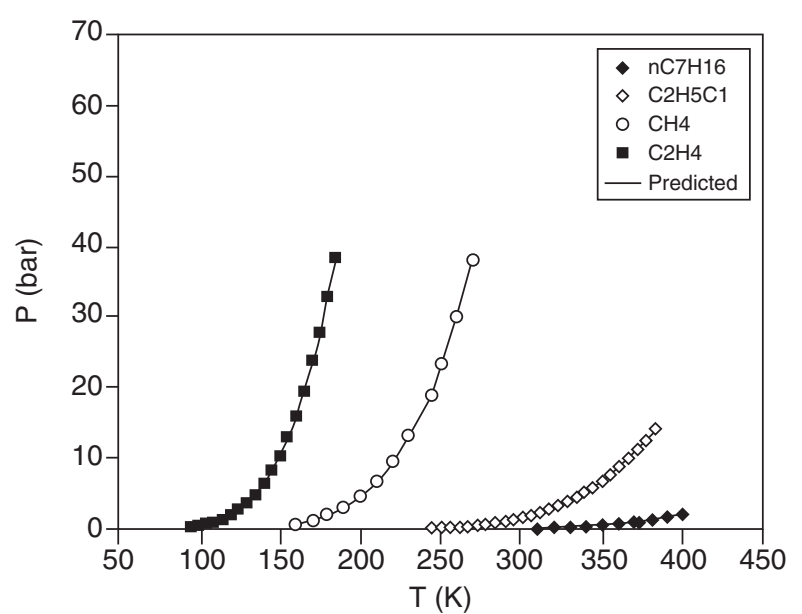

Figure 1

The vapor pressure of different hydrocarbons vs. temperature. (experimental data from R.H. Perry and D.W. Green, 1988).

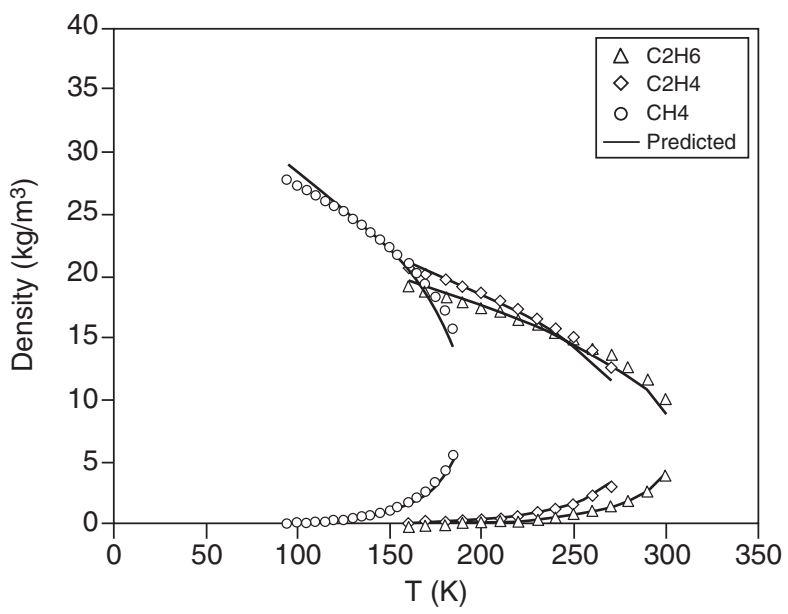

Figure 2

Experimental and predicted liquid and vapor densities of three hydrocarbons as a function of reduced temperature (experimental data from R.H. Perry and D.W. Green, 1988).

show that there is good agreement between the experimental data and the results of the new equation of state.

Figure 5 illustrates the pressure - density diagram of $\mathrm{CH}_{4}$. There is acceptable agreement between the predictions and the experimental values for both the saturated liquid and the saturated vapor.

The proposed equation of state is applied for mixture VLE calculations. For this work, mixing rules are needed. The 
TABLE 2

Thermodynamic relations for calculating thermodynamic properties using Equation (4)

\begin{tabular}{|c|c|}
\hline The EOS in terms of $A, B$ and $Z$ & $\begin{array}{l}Z^{3}-Z^{2}+\left(A-B^{2}-2 B\right) Z-\left(A B+B^{2}\right)=0 \\
A=\frac{a P}{R^{2} T^{2}}, \quad B=\frac{b P}{R T} \text { and } Z=\frac{P v}{R T}\end{array}$ \\
\hline Fugacity coefficient of Component $i$ in mixture & $\begin{aligned} \ln \left(\phi_{i} Z\right) & =2\left[\frac{\partial\left(n b_{m}\right) / \partial n_{i}}{v-b_{m}}-\ln \left(1-\frac{b_{m}}{v}\right)\right]-\frac{a_{m} /\left(b_{m} R T\right)}{v+b_{m}} \frac{\partial\left(n b_{m}\right)}{\partial n_{i}} \\
& +\frac{a_{m}}{b_{m} R T}\left\{\frac{1}{a_{m}}\left[\frac{1}{n} \frac{\partial\left(n^{2} a_{m}\right)}{\partial n_{i}}\right]-\frac{1}{b_{m}} \frac{\partial\left(n b_{m}\right)}{\partial n_{i}}\right\} \ln \left(\frac{v}{v+b_{m}}\right.\end{aligned}$ \\
\hline Enthalpy departure & $\begin{aligned} H-H^{*}= & R T(Z-1)+\frac{1}{b}\left(T \frac{d a}{d T}-a-\frac{a T}{b} \frac{d b}{d T}\right) \ln \left(1+\frac{B}{Z}\right) \\
& -2 P T \frac{(d b / d T)}{Z-B}+\frac{a P}{R b} \frac{(d b / d T)}{Z+B}\end{aligned}$ \\
\hline Entropy departure & $\begin{aligned} S-S^{*} & =2 R \ln \left(1-\frac{B}{Z}\right)+\frac{1}{b}\left(\frac{d a}{d T}-\frac{a}{b} \frac{d b}{d T}\right) \ln \left(1+\frac{B}{Z}\right) \\
& -2 P \frac{(d b / d T)}{Z-B}+\frac{a P}{R b} \frac{(d b / d T)}{Z+B}\end{aligned}$ \\
\hline
\end{tabular}

TABLE 3

Prediction of vapor pressure, saturated liquid density and the vapor volume of pure fluids from various equations of state

\begin{tabular}{|c|c|c|c|c|c|c|c|c|c|c|c|c|}
\hline \multirow{3}{*}{ Hydrocarbon } & \multirow{3}{*}{$\mathrm{np}$} & \multirow{3}{*}{$\mathrm{T}_{\mathrm{r}}$ range } & \multicolumn{9}{|c|}{ Percent of average absolute deviation (\%AAD) } & \multirow{3}{*}{ Ref } \\
\hline & & & \multicolumn{3}{|c|}{ Vapor Pressure } & \multicolumn{3}{|c|}{ Saturated liquid density } & \multicolumn{3}{|c|}{ Vapor volume } & \\
\hline & & & New & PR & SRK & New & PR & SRK & New & PR & SRK & \\
\hline $\mathrm{CH}_{4}$ & 19 & $0.50-0.97$ & 0.741 & 0.584 & 1.820 & 4.095 & 8.886 & 4.472 & 1.792 & 0.930 & 2.335 & $*$ \\
\hline $\mathrm{C}_{2} \mathrm{H}_{6}$ & 15 & $0.52-0.98$ & 0.408 & 0.757 & 1.216 & 5.210 & 6.570 & 7.775 & 1.751 & 1.173 & 1.075 & * \\
\hline $\mathrm{C}_{3} \mathrm{H}_{8}$ & 17 & $0.51-0.95$ & 0.637 & 1.401 & 0.758 & 4.426 & 5.049 & 8.164 & 1.535 & 1.571 & 0.318 & $*$ \\
\hline$n-\mathrm{C}_{4} \mathrm{H}_{10}$ & 20 & 0.54-0.99 & 0.499 & 0.814 & 1.037 & 6.088 & 4.875 & 10.479 & 2.243 & 1.138 & 0.717 & * \\
\hline$i-\mathrm{C}_{4} \mathrm{H}_{10}$ & 17 & $0.54-0.98$ & 0.962 & 1.569 & 1.658 & 5.697 & 5.216 & 9.518 & 2.132 & 2.179 & 1.479 & $*$ \\
\hline$n-\mathrm{C}_{5} \mathrm{H}_{12}$ & 22 & $0.64-0.97$ & 0.606 & 0.348 & 1.061 & 5.858 & 3.379 & 12.236 & 2.782 & 1.103 & 0.713 & $* *$ \\
\hline$i-\mathrm{C}_{5} \mathrm{H}_{12}$ & 28 & $0.53-0.97$ & 1.219 & 0.244 & 1.348 & 6.260 & 4.747 & 10.420 & 2.459 & 1.219 & 1.449 & $* *$ \\
\hline$n-\mathrm{C}_{6} \mathrm{H}_{14}$ & 31 & $0.53-0.97$ & 1.368 & 1.021 & 1.770 & 6.331 & 2.894 & 12.737 & 3.793 & 1.635 & 1.597 & $* *$ \\
\hline$n-\mathrm{C}_{7} \mathrm{H}_{16}$ & 11 & $0.57-0.74$ & 0.598 & 1.676 & 0.663 & 2.995 & 0.698 & 12.140 & 0.665 & 1.773 & 0.516 & $*$ \\
\hline$n-\mathrm{C}_{8} \mathrm{H}_{18}$ & 12 & $0.60-0.98$ & 0.426 & 1.590 & 1.797 & 7.839 & 5.916 & 16.758 & 5.273 & 1.961 & 2.248 & $*$ \\
\hline$n-\mathrm{C}_{9} \mathrm{H}_{20}$ & 14 & $0.50-0.94$ & 3.757 & 2.389 & 2.231 & 7.198 & 4.953 & 15.904 & 12.495 & 6.778 & 6.638 & $*$ \\
\hline$n-\mathrm{C}_{10} \mathrm{H}_{22}$ & 14 & $0.55-0.94$ & 2.377 & 2.362 & 1.819 & 7.197 & 7.428 & 18.132 & 6.464 & 1.928 & 2.179 & $*$ \\
\hline $\mathrm{C}_{2} \mathrm{H}_{4}$ & 12 & $0.57-0.96$ & 0.501 & 0.658 & 0.808 & 4.396 & 6.197 & 7.215 & 1.444 & 1.189 & 0.575 & $*$ \\
\hline $\mathrm{C}_{3} \mathrm{H}_{6}$ & 19 & $0.52-0.98$ & 0.677 & 1.487 & 0.900 & 4.921 & 6.612 & 7.128 & 1.982 & 1.482 & 0.387 & * \\
\hline $\mathrm{C}_{7} \mathrm{H}_{14}$ & 28 & $0.55-0.97$ & 0.735 & 0.788 & 0.822 & 5.786 & 3.802 & 11.179 & 3.054 & 1.229 & 0.975 & $* *$ \\
\hline $\mathrm{C}_{2} \mathrm{H}_{2}$ & 12 & $0.65-0.97$ & 0.884 & 1.496 & 2.275 & 6.513 & 4.192 & 11.429 & 3.824 & 1.248 & 1.372 & $*$ \\
\hline $\mathrm{C}_{6} \mathrm{H}_{6}$ & 25 & $0.55-0.98$ & 0.626 & 0.908 & 0.681 & 5.270 & 3.166 & 11.216 & 2.554 & 1.167 & 0.717 & $*$ \\
\hline $\mathrm{C}_{6} \mathrm{H}_{5} \mathrm{CH}_{3}$ & 20 & $0.51-0.98$ & 1.751 & 1.339 & 1.148 & 5.570 & 2.447 & 13.273 & 2.953 & 2.557 & 1.874 & $*$ \\
\hline $\mathrm{C}_{3} \mathrm{H}_{6} \mathrm{O}$ & 20 & $0.59-0.94$ & 2.501 & 2.288 & 1.631 & 13.428 & 12.236 & 22.475 & 4.470 & 2.488 & 2.207 & $*$ \\
\hline $\mathrm{CH}_{3} \mathrm{Cl}$ & 36 & $0.51-0.96$ & 0.943 & 0.661 & 1.233 & 7.243 & 2.093 & 12.867 & 4.134 & 1.768 & 3.188 & $* *$ \\
\hline
\end{tabular}

* Perry, R.H. and Green, D.W. (1988) Perry's Chemical Engineers' Handbook, 6th Edition, McGraw Hill, Tokyo, Japan.

** Smith, B.D. and Srivastava, R. (1986) Thermodynamic Data for Pure Compounds, Elsevier. 


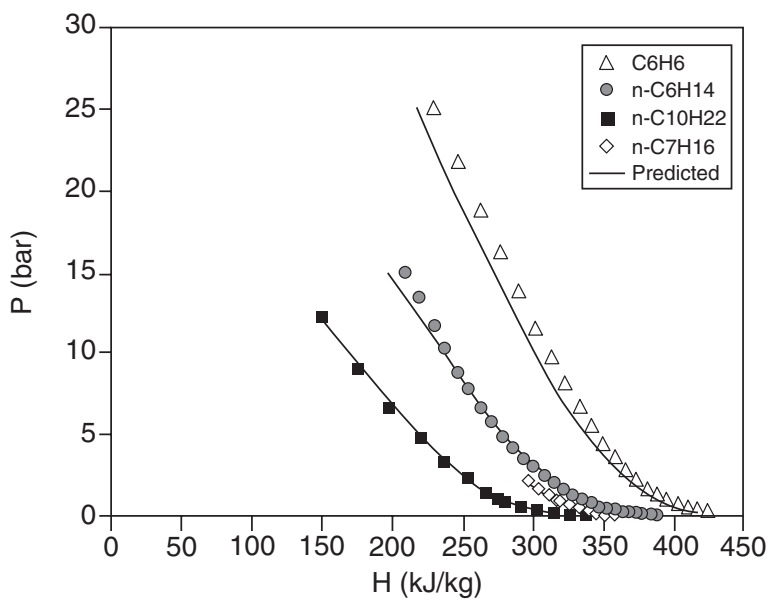

Figure 3

Pressure-enthalpy phase behavior for many hydrocarbons (experimental data from R.H. Perry, D.W. Green, 1988; B.D. Smith, R. Srivastava).

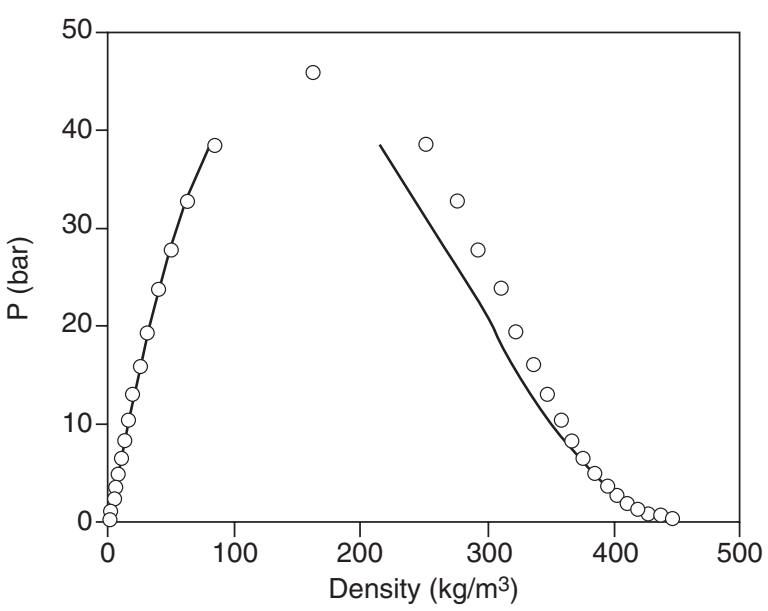

Figure 5

Experimental and predicted pressure-density for $\mathrm{CH}_{4}$ (experimental data from Vargaftik, N.B., 1975).

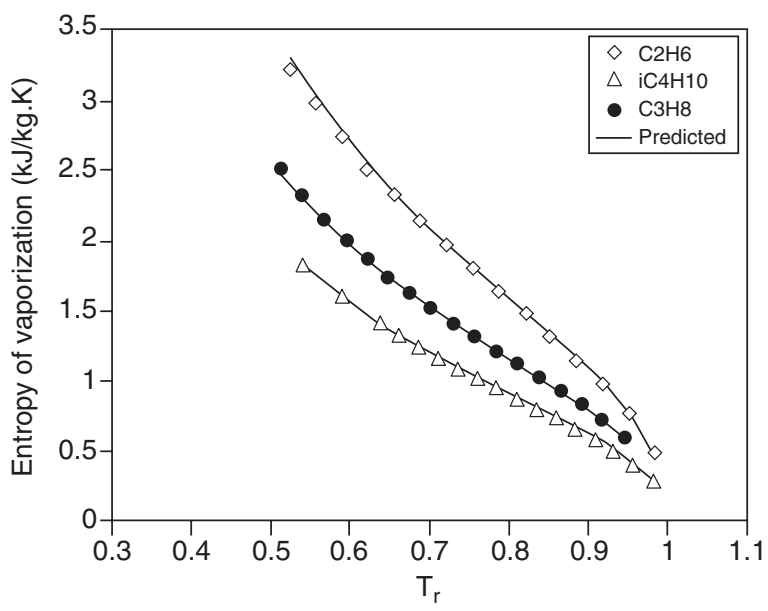

Figure 4

Experimental and predicted entropy of different fluids as a function of reduced temperature (experimental data from R.H. Perry, D.W. Green, 1988)

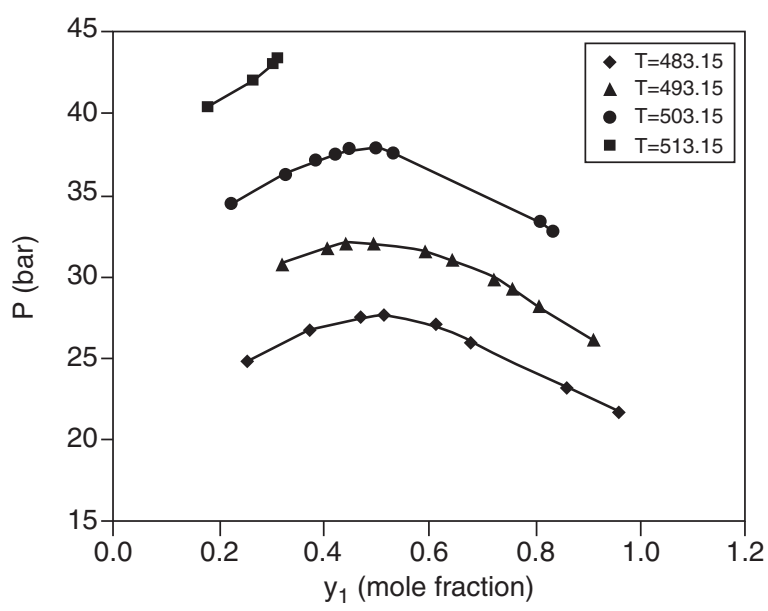

Figure 6

Pressure-equilibrium phase composition for $n$-hexane+1propanol (experimental data from Oh et al., 2004).
vdW mixing rules for two parameter equations of state usually are used:

$$
\begin{gathered}
a=\sum_{i}^{n} \sum_{j}^{n} x_{i} x_{j}\left(a_{i i} a_{j j}\right)^{0.5}\left(1-k_{i j}\right) \\
b=\sum_{i}^{n} x_{i} b_{i}
\end{gathered}
$$

where $k_{i j}$ is the binary interaction parameter.
The new cubic equation of state is used for the vaporliquid equilibrium (VLE) calculations of 10 different binary fluid mixtures for which experimental data are available. Table 5 compares results of the VLE calculations using the present equation of state, the PR equation of state and the SRK equation of state with assumption $k_{i j}=0$ for all these equations. According to this table the new cubic equation of state is overall superior of the other equations for the mixtures. In Figure 6 the phase behavior of $n$-hexane+1propanol binary systems are plotted. As seen in these figure, 
TABLE 4

Prediction of the enthalpy and the entropy of pure fluids from various equations of state

\begin{tabular}{|c|c|c|c|c|c|c|c|c|c|}
\hline \multirow{3}{*}{ Hydrocarbon } & \multirow{3}{*}{$\mathrm{np}$} & \multirow{3}{*}{$\mathrm{T}_{\mathrm{r}}$ range } & \multicolumn{6}{|c|}{ Percent of average absolute deviation (\%AAD) } & \multirow{3}{*}{ Ref. } \\
\hline & & & \multicolumn{3}{|c|}{ Enthalpy of vaporization } & \multicolumn{3}{|c|}{ Entropy of vaporization } & \\
\hline & & & New & PR & SRK & New & PR & SRK & \\
\hline $\mathrm{CH}_{4}$ & 19 & $0.50-0.97$ & 1.261 & 1.418 & 2.486 & 2.101 & 2.394 & 3.373 & $*$ \\
\hline $\mathrm{C}_{2} \mathrm{H}_{6}$ & 15 & $0.52-0.98$ & 1.543 & 1.794 & 2.619 & 1.538 & 1.804 & 2.624 & $*$ \\
\hline $\mathrm{C}_{3} \mathrm{H}_{8}$ & 17 & $0.51-0.95$ & 0.806 & 1.308 & 1.048 & 0.808 & 1.304 & 1.050 & $*$ \\
\hline$n-\mathrm{C}_{4} \mathrm{H}_{10}$ & 20 & $0.54-0.99$ & 1.980 & 2.083 & 2.767 & 1.912 & 2.015 & 2.700 & * \\
\hline$i-\mathrm{C}_{4} \mathrm{H}_{10}$ & 17 & $0.54-0.98$ & 1.555 & 1.343 & 1.216 & 1.530 & 1.354 & 1.237 & $*$ \\
\hline$n-\mathrm{C}_{5} \mathrm{H}_{12}$ & 22 & $0.64-0.97$ & 1.672 & 1.428 & 2.200 & - & - & - & $* *$ \\
\hline$i-\mathrm{C}_{5} \mathrm{H}_{12}$ & 28 & $0.53-0.97$ & 1.709 & 1.768 & 2.547 & - & - & - & $*$ \\
\hline$n-\mathrm{C}_{6} \mathrm{H}_{14}$ & 31 & $0.53-0.97$ & 2.983 & 2.368 & 2.968 & - & - & - & $* *$ \\
\hline$n-\mathrm{C}_{7} \mathrm{H}_{16}$ & 11 & $0.57-0.74$ & 1.593 & 0.591 & 1.194 & 1.602 & 0.576 & 1.203 & $*$ \\
\hline$n-\mathrm{C}_{8} \mathrm{H}_{18}$ & 12 & $0.60-0.98$ & 4.425 & 3.269 & 4.167 & 4.487 & 3.294 & 4.197 & $*$ \\
\hline$n-\mathrm{C}_{9} \mathrm{H}_{20}$ & 14 & $0.50-0.94$ & 6.191 & 4.956 & 5.282 & 6.381 & 7.442 & 7.817 & $*$ \\
\hline$n-\mathrm{C}_{10} \mathrm{H}_{22}$ & 14 & $0.55-0.94$ & 4.753 & 1.527 & 2.306 & 4.653 & 1.444 & 2.213 & $*$ \\
\hline $\mathrm{C}_{2} \mathrm{H}_{4}$ & 12 & $0.57-0.96$ & 0.739 & 1.240 & 1.662 & 1.182 & 2.360 & 2.785 & $*$ \\
\hline $\mathrm{C}_{3} \mathrm{H}_{6}$ & 19 & $0.52-0.98$ & 1.272 & 1.691 & 1.704 & 1.281 & 1.699 & 1.717 & $*$ \\
\hline $\mathrm{C}_{7} \mathrm{H}_{14}$ & 28 & $0.55-0.97$ & 2.151 & 1.450 & 1.813 & - & - & - & $* *$ \\
\hline $\mathrm{C}_{2} \mathrm{H}_{2}$ & 12 & $0.65-0.97$ & 3.613 & 3.804 & 4.431 & 3.563 & 1.337 & 4.463 & $*$ \\
\hline $\mathrm{C}_{6} \mathrm{H}_{6}$ & 25 & $0.55-0.98$ & 1.456 & 1.317 & 1.403 & 2.368 & 2.354 & 2.235 & $*$ \\
\hline $\mathrm{C}_{6} \mathrm{H}_{5} \mathrm{CH}_{3}$ & 20 & $0.51-0.98$ & 2.550 & 2.936 & 3.268 & 2.542 & 2.958 & 3.240 & $*$ \\
\hline $\mathrm{C}_{3} \mathrm{H}_{6} \mathrm{O}$ & 20 & $0.59-0.94$ & 5.848 & 3.839 & 4.697 & 4.766 & 2.524 & 4.273 & $*$ \\
\hline $\mathrm{CH}_{3} \mathrm{Cl}$ & 36 & $0.51-0.96$ & 3.086 & 1.420 & 2.604 & - & - & - & $* *$ \\
\hline
\end{tabular}

* R.H. Perry, D.W. Green, Perry's Chemical Engineers' Handbook, 6th Edition, McGraw Hill, Tokyo, Japan, (1988).

** B.D. Smith, R. Srivastava, Thermodynamic data for pure compounds, Elsevier (1986).

TABLE 5

Relative error in the calculated pressure and vapor phase composition for various binary mixtures

\begin{tabular}{|c|c|c|c|c|c|c|c|c|}
\hline \multirow{3}{*}{ Systems } & \multirow{3}{*}{$\mathrm{np}$} & \multicolumn{6}{|c|}{ Percent of average absolute deviation (\%AAD) } & \multirow{3}{*}{ Ref. } \\
\hline & & \multicolumn{3}{|c|}{ Bubble Pressure } & \multicolumn{3}{|c|}{ Vapor mole fraction } & \\
\hline & & New & PR & SRK & New & PR & SRK & \\
\hline 1-Butene +1 -Hexene & 6 & 4.934 & 1.644 & 0.895 & 5.049 & 1.382 & 1.621 & I \\
\hline $\mathrm{CO}_{2}+$ iso-butanol & 31 & 17.630 & 36.600 & 35.191 & 0.728 & 0.667 & 0.692 & II \\
\hline $\mathrm{CO}_{2}+$ iso-pentanol & 51 & 5.636 & 33.182 & 31.720 & 1.203 & 1.183 & 1.197 & II \\
\hline $\mathrm{CO}_{2}+\mathrm{CHC}_{13}$ & 30 & 5.901 & 16.384 & 15.096 & 7.836 & 25.738 & 25.900 & III \\
\hline $\mathrm{CO}_{2}+$ toluene & 45 & 16.578 & 36.002 & 35.422 & 2.087 & 1.949 & 2.034 & III \\
\hline $\mathrm{C}_{2} \mathrm{H}_{6}+\mathrm{CO}_{2}$ & 14 & 19.122 & 22.922 & 22.777 & 2.538 & 5.226 & 5.017 & IV \\
\hline $\mathrm{CO}_{2}+\mathrm{n}-\mathrm{C}_{4} \mathrm{H}_{10}$ & 38 & 9.843 & 17.655 & 17.674 & 7.640 & 17.978 & 18.411 & IV \\
\hline $\mathrm{C}_{6} \mathrm{H}_{6}+\mathrm{C}_{6} \mathrm{H}_{5} \mathrm{Cl}$ & 7 & 6.346 & 3.759 & 3.343 & 1.178 & 2.706 & 1.659 & IV \\
\hline Methanol + 2-butanone & 10 & 4.910 & 6.785 & 6.964 & - & - & - & IV \\
\hline $\mathrm{N}_{2}+\mathrm{CH}_{4}$ & 24 & 8.950 & 9.506 & 9.248 & 0.728 & 1.318 & 1.231 & IV \\
\hline Average & 256 & 9.985 & 18.443 & 17.833 & 3.220 & 6.460 & 6.418 & \\
\hline
\end{tabular}

I Laugier and Richon, 1996; II da Silva and Barbosa, 2002; III Scurto et al., 2001; IV Winnick, 1997. 
there is good agreement between the calculated and experimental values, in these systems.

\section{CONCLUSIONS}

A cubic equation of state based on hard-core model has been developed to predict phase behavior of pure hydrocarbons and mixtures. This equation of state predicts accurately the vapor pressure and liquid density of pure hydrocarbons. Using the new cubic equation of state, VLE have been calculated.

The prediction ability of this cubic equation of state for predicting thermal properties is comparable to the PR and SRK equation of state.

\section{REFERENCES}

Da Silva, M.V and Barbosa, D. (2002) High Pressure VaporLiquid Equilibrium Data for the Systems Carbon Dioxide/2Methyl-1-Propanol and Carbon Dioxide/3-Nethyl-1-Butanol at 288.2, 303.2 and 313.2 K. Fluid Phase Equil., 198, 229-237.

Hartono, R., Mansoori, G.A. and Suwono, A. (1999) Prediction of Molar Volumes, Vapor Pressures and Supercritical Solubilities of Alkanes by Equation of State. Chem. Eng. Comm., 173, 23-42.

Johnston, K.P., Ziger, D.H. and Eckert, C.A. (1982) Solubilities of Hydrocarbon Solid in Supercritical Fluids. The Augmented Van der Waals Treatment. Ind. Eng. Chem. Fundam., 21, 191-197.

Laugier, S. and Richon, D. (1996) High-Pressure Vapor-Liquid Equilibria for Ethylene+4-Methyl-1-Pentene and 1-Butene+1Hexene. J. Chem. Eng. Data, 41, 282-284.

Madras, G., Kulkarni, C. and Modak, J. (2003) Modeling the Solubilities of Fatty Acids in Supercritical Carbon Dioxide. Fluid Phase Equil., 209, 207-213.

Malanowski, S. and Anderko, A. (1992) Modeling Phase Equilibria, Second Edition, John Wiley, New York.

Mohsen-Nia, M., Modarres, H. and Mansoori, G.A. (1995) A Cubic Equation of State Based on a Simplified Hard-Core Model. Chem. Eng. Comm., 131, 15-31.
Mohsen-Nia, M., Modarres, H. and Mansoori, G.A. (2003) A Cubic Hard-Core Equation of State. Fluid Phase Equil., 206, 27 39.

Nasrifar, Kh. and Moshfeghian, M. (2004) Application of an Improved Equation of State to Reservoir Fluids: Computation of Minimum Miscibility Pressure. J. Pet. Sci. Eng., 42, 223-234.

Oh, B.C., Kim, Y., Shin, H.Y. and Kim, H. (2004) Vapor-Liquid Equilibria for the System 1-Propanol $+n$-hexane Near the Critical Region. Fluid Phase Equil., 15, 41-46.

Patel, N.C. and Teja, A.S. (1982) A New Cubic Equation of State for Fluids and Fluid Mixtures. Chem. Eng. Sci., 37, 463473

Peng, D.Y. and Robinson, D.B. (1976) A New Two-Constant Equation of State. Ind. Eng. Chem. Fundam., 15, 59-64.

Perry, R.H. and Green, D.W. (1988) Perry's Chemical Engineers' Handbook, Sixth Edition, McGraw Hill, Tokyo.

Redlich, O. and Kwong, J.N.S. (1949) On the Thermodynamics of Solutions, V: An Equation of State. Fugacities of Gaseous Solutions. Chem. Rev., 44, 233-244.

Riazi, M.R. and Mansoori, G.A. (1993) Simple Equation of State accurately Predicts Hydrocarbon Densities. Oil and Gas J., July $12,108-111$.

Scurto, A.M., Lubbers, C.M., Xu, G. and Brennecke, J.F. (2001) Experimental Measurement and Modeling of the Vapor-Liquid Equilibrium of Carbon Dioxide + Chloroform. Fluid Phase Equil., 190, 135-147.

Smith, B.D. and Srivastava, R. (1986) Thermodynamic Data for Pure Compounds, Elsevier.

Soave, G. (1972) Equilibrium Constants from a Modified Redlich-Kwong Equation of State. Chem. Eng. Sci., 72, 11971203.

Valderrama, J.O. (1990) A Generalized Patel-Teja Equation of State for Polar and Nonpolar Fluids and Mixtures. J. Chem. Eng. Japan, 23, 87-91.

Van der Waals, J.D. (1873) PhD. Dissertation, Leiden.

Vargaftik, N.B. (1975) Handbook of Physical Properties of Liquids and Gases (Pure Substances and Mixtures), Second Edition, English Translation, Hemisphere Publication, Washington, DC.

Winnick, J. (1997) Chemical Engineering Thermodynamics, John Wiley, New York.

Final manuscript received in June 2005

Copyright $(\mathbb{C} 2006$ Institut français du pétrole

Permission to make digital or hard copies of part or all of this work for personal or classroom use is granted without fee provided that copies are not made or distributed for profit or commercial advantage and that copies bear this notice and the full citation on the first page. Copyrights for components of this work owned by others than IFP must be honored. Abstracting with credit is permitted. To copy otherwise, to republish, to post on servers, or to redistribute to lists, requires prior specific permission and/or a fee. Request permission from Documentation, Institut français du pétrole, fax. +33147527078 , or revueogst@ifp.fr. 